\title{
Reflexões sobre aspectos da obra de H. P. Lovecraft
}

\author{
Leandro Antonio de Almeida
}

RÉSUMÉ: Le présent article se propose d'analyser les nouvelles Arthur Jermin (1920) et La peur qui rôde (1922) de H. P. Lovecraft. L'étude porte sur le monde surnaturel créé par l'auteur, le protagoniste de chaque nouvelle et la question de la peur, tout en établissant un lien entre ces items et le moment historique vécu par l'auteur. Les éléments présentés obéissent à un ordre, c'està-dire qu'ils partent du monde tel qu'il est constitué (dans la fiction de l'auteur) et vont jusqu'à l'effet provoqué, en passant par la façon dont le protagoniste perçoit I' «inconnu », l'objectif étant de mettre en évidence ce que l'auteur recherchait à travers ses ouvrages : faire peur au lecteur.

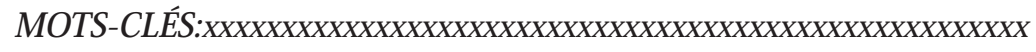

\section{Introdução}

Nossa proposta é analisar algumas questões que consideramos centrais da obra de Lovecraft: o mundo sobrenatural por ele criado, a questão da compreensão no protagonista lovecraftiano e a questão do medo, relacionando-as ao momento histórico vivido pelo autor. Esses elementos apresentavam-se aos homens de época de duas maneiras: eram problemáticas colocadas pelo seu tempo e/ou soluções por eles encontradas para expressar simbolicamente seus anseios, e tomaram uma forma específica no caso de Lovecraft. A ordem na qual os elementos serão apresentados, partindo do mundo tal como este é constituído (na ficção do autor), passando pelo modo como o protagonista encara (conhece) o "desconhecido" e finalizando com o efeito daí decorrente, visa dar um destaque aquilo que o autor buscava em suas obras: causar medo no leitor.

Leandro Antonio de Almeida é mestrando em História na Universidade de São Paulo. 
Howard Philips Lovecraft (1890-1937) nasceu e cresceu em Providence (Rhode Island - EUA), cidade que foi cenário de muitos de seus contos. Membro da classe média norte-americana de origem aristocrática, foi uma criança bastante precoce nas letras, iniciando suas leituras aos três anos e escrevendo seus primeiros textos por volta dos sete. O interesse por histórias sobrenaturais veio das histórias góticas contadas por seu avô. Um dos autores que mais o influenciou foi Edgar Allan Poe ${ }^{1}$. Também gostava de Ciência e História que vão permear seus contos, dando-lhes um caráter de verossimilhança bastante peculiar. Sua produção ficcional manteve-se fragmentada, sendo apenas publicada em revistas literárias (Lovecraft nunca teve um livro publicado em vida). Somente após a sua morte que seus amigos reuniram e publicaram seus contos. Isso não significa que ele não se tornasse um intelectual de renome no meio amador, pois, além de se tornar escritor profissional, foi presidente de duas associações nacionais de escritores amadores, através das quais conseguiu configurar suas principais amizades, com as quais manteve uma vastíssima correspondência até o fim da vida ${ }^{2}$.

Os contos aqui analisados, "Facts Concerning the Late Arthur Jermyn and His Family" (1920) e "The lurking fear" (1922) ${ }^{3}$, pertencem a um período da produção literária do autor iniciado em 1914, no qual a ênfase estava na poesia e nos ensaios, sendo sua produção de histórias sobrenaturais esparsa, mas contínua. A produção de histórias de horror sobrenatural vai aumentar a partir de 1922, quando Lovecraft se tornará mais conhecido nesse gênero ${ }^{4}$.

\section{Estrutura dos contos}

No primeiro dos contos, "Facts Concerning the Late Arthur Jermyn and His Family", o narrador inicia contando como foi a morte de Arthur Jermyn, que ateou fogo em si mesmo após receber um caixote vindo da África. Em

\footnotetext{
1 "When I write stories, Edgar Allan Poe is my model." Trecho da carta a Rheinhart Kleiner, de 20 de Janeiro de 1916, extraída do site http://www.hplovecraft.com/life/interest/ authors.htm\#poe

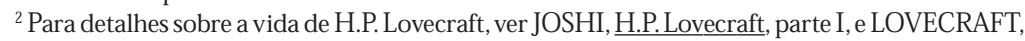
An autobiographical sketch

${ }^{3}$ Em português ambos os contos foram publicados em: LOVECRAFT, H.P. Dagon São Paulo: Iluminuras, 2001

${ }^{4}$ JOSHI, op. cit., parte I, § 6
} 
seguida, é descrita a genealogia paterna do protagonista a partir de seu trisavô Wade, que viveu em meados do século XVIII e que foi considerado louco por contar histórias sobre uma cidade perdida no Congo onde habitavam homens macacos que cultuavam uma deusa empalhada (onde esteve e casou-se com uma filha de um comerciante português). Depois é relatado o destino de todos os descendentes de Wade: Philip, Robert e Alfred, pai de Arthur.

Na segunda parte do conto, a narrativa mostra como Arthur tornou-se etnólogo e como se interessou em estudar os manuscritos e os artefatos estranhos deixados por seu trisavô, indo até a África para obter mais informações sobre os mitos das tribos locais que, segundo Arthur, teriam enlouquecido seu antepassado. Lá, recolhe relatos orais sobre tais mitos e, através de um contato no governo belga, obtém meios de conseguir a deusa empalhada para estudos. Ao recebê-la, tempos depois, nota que ela se assemelha a si mesmo e possui o brasão da família num medalhão. Horrorizado por saber que era sua antepassada, ateia fogo em si mesmo. A história é narrada em terceira pessoa (narrador não onisciente), mas com um caráter indiciário, como se quem contasse estivesse colhido relatos de pessoas que viam e conheciam Arthur Jermyn e dado um sentido a eles.

A segunda narrativa, "The Lurking Fear", em primeira pessoa, conta como um estudioso de horror, após obter notícias sobre uma possível criatura que ataca os aldeões nas noites tempestuosas, dirige-se ao local para investigar o caso. Segundo lendas camponesas, a criatura estaria à espreita no alto de uma montanha onde há uma casa antiga e abandonada que pertenceu à família Martense, colocada no ostracismo pelos aldeões após um deles ter sido assassinado em meados do século XIX. Após algumas tentativas mal-sucedidas de investigação, nas quais os acompanhantes do protagonista morriam, ele acaba descobrindo a natureza e o modus operandi da(s) criatura(s), que marcam-no pelo resto da vida.

Nos dois contos, como em boa parte da obra do autor, o protagonista está plenamente inserido na cultura letrada ocidental (num caso, ele é antropólogo e, no outro, um estudioso do horror). Desse modo, enquadrado nos cânones da ciência, quando confrontado com indícios do sobrenatural, ele se mostra cético, mas instigado a investigá-los.

Esses indícios se apresentam de uma dupla forma: diretamente, por meio de artefatos ou por eventos estranhos presenciados, e indiretamente, por meio de relatos (muitas vezes orais). O motivo do ceticismo para o protagonista é que os relatos orais não merecem crédito, pois denunciam a ignorância de seus enunciadores (como a memória de um antepassado 
louco e mitos de tribos da África, no primeiro caso, e os relatos dos camponeses, no segundo) ${ }^{5}$. No desenrolar da narrativa ele vai se defrontando com mais indícios daquilo em que não acreditava até um clímax, geralmente no final da história, no qual ele apreende, diante de si, a plenitude e o sentido dessa realidade sobrenatural, que abala suas certezas fundamentadas e faz com que ele perca, nos melhores casos, parte de (ou toda) sua sanidade e, nos piores, a vida, por não suportar o medo daquilo com que se defronta ${ }^{6}$. Apesar do realismo com que Lovecraft procura marcar seus contos, estes não são relatados por um observador externo e alheio aos eventos (como na narrativa realista/naturalista do final do século XIX) ${ }^{7}$, mas, quando não pelo próprio protagonista (que vive os eventos insólitos), por alguém muito próximo a ele. O elemento de subjetividade é bem marcante, dando margem a uma possibilidade de dúvida por parte do leitor sobre a veracidade daquilo que é contado pelo narrador (principalmente quando a história é narrada em primeira pessoa), mas que este afirma incessantemente ser verdade ${ }^{8}$. Vamos trabalhar com o pressuposto de o que é contado nas histórias não é mero delírio da mente do protagonista, mas algo verossímil dentro da construção do mundo ficcional de Lovecraft.

\section{Os três mundos}

A partir do que foi colocado, vemos presente e inter-relacionados três mundos distintos: o mundo "civilizado", com os paradigmas da ciência do tempo de Lovecraft, expresso no protagonista; o mundo da tradição oral, presente em lugares distantes dos centros urbanos, representados pelos camponeses iletrados ou membros de tribos "primitivas"; e o mundo sobrenatural, onde estão presentes criaturas estranhas que existiam muito antes do homem surgir na terra. Este último, para o autor, é de natureza superior, com

5 "No one outside the backwoods had believed these varying and conflicting stories, with their incoherent, extravagant descriptions of the hall-glimpsed fiend" - LOVECRAFT, Lurking Fear, $\$ 6$ (parte I)

6 "Arthur Jermyn went out on the moor and burned himself after seeing the boxed object which had come from Africa. It was this object, and not his peculiar personal appearance, which made him end his life" LOVECRAFT, Facts Concerning the Late Arthur Jermyn and His Family, $\$ 2$ (parte I)

${ }^{7}$ TAYLOR, História das Letras Americanas, p. 308

8 "Would to God I had let them share the search, that I might not have had to bear the secret alone so long; to bear it alone for fear the world call me mad or go mad it itself at the demon implications of the thing" - LOVECRAFT, Lurking Fear, §2 (parte I) 
seres conscientes que têm poder para aniquilar, se quiserem, a humanidade.

Entretanto, podemos dizer que este mundo antigo está isolado e velado no momento, não se manifestando ativamente em todo o planeta (apenas em lugares restritos), mas ainda permanece na memória coletiva de culturas orais das localidades onde se manifesta (e se manifestaram outrora). É por intermédio dessa memória, transmitida de geração em geração, que os protagonistas têm uma primeira notícia do mundo sobrenatural. O sobrenatural, em Lovecraft, manifesta-se em locais longe da "civilização" e convive com a cultura tradicional, sendo sua presença na localidade muito antiga ${ }^{9}$. Se aliarmos a isso o caráter narrativo presente nessas culturas ${ }^{10}$, os eventos concernentes a esse sobrenatural são apenas contados, tendo como fim uma sabedoria que ensina a ficar longe dessa antiga ameaça ${ }^{11}$. Esse aviso é passado ao protagonista, que o rejeita em nome do conhecimento e da necessidade da explicação ${ }^{12}$. Dessa forma, há uma tensão entre a experiência vivida e transmitida local e oralmente e o conhecimento abstrato, externo e teórico, que tenta impor uma explicação alheia ao meio mesmo sem conhecê-lo. Não nos esqueçamos de que, nos dois contos, as personagens principais são estrangeiras aos locais de onde provêm os eventos estranhos.

Historicamente, essa tensão vai ser resolvida em prol de uma cultura cuja valorização de um conhecimento abstrato e universal (Europa Ocidental e EUA, no século XIX) vai se impor tanto a populações rurais dos países em industrialização quanto de populações tradicionais da Ásia, América e África. Nos contos de Lovecraft, temos uma inversão disso, pois suas personagens caminham de um ceticismo, em relação às evidências e relatos, para uma revisão (quando não recusa) de seus próprios paradigmas, ou seja, as personagens pendem para a compreensão (e aceitação) da existência de uma realidade antes tida como sobrenatural por se verem impotentes diante das muitas evidências de sua presença e, conseqüentemente, começam a dar crédito aos relatos provenientes do imaginário tradicional, até se defrontarem com o objeto de sua busca.

\footnotetext{
${ }^{9}$ Aqui não trabalharemos com os contos ambientados em cidades. Todavia, podemos aproxima-los dos aqui tratados, pois o sobrenatural aparece em locais de baixa extração social, como em "The Horror at Red Hook", "He", "Cool Air", entre outros.

${ }^{10}$ BENJAMIN, O narrador, p. 198 e p. 200

${ }_{11}$ "Meanwhile there grew up about the mansion and the mountain a body of diabolic legendry. The place was avoided with doubled assiduousness, and invested with every whispered myth tradition could supply" - LOVECRAFT, Lurking Fear, \$43 (parte III)

12"a informação aspira a verificação imediata. Antes de mais nada, ela precisa ser compreensível 'em si e para si' " BENJAMIN, op. cit., p.203
} 


\section{Desvelamento e Compreensão no protagonista Lovecraftiano}

A compreensão é feita num lapso instantâneo que dá um sentido a tudo o que vinha ocorrendo na narrativa (eventos, indícios, relatos etc.), sendo isso que permite Lovecraft começar pelo fim em ambos os contos sem comprometer a trama. $\mathrm{O}$ protagonista vai acumulando informações segundo procedimentos científicos que ele julga eficientes para dar conta de entender e explicar cientificamente os eventos estranhos. Todavia, a explicação satisfatória daquilo que se apresenta, no fim da narrativa, tal como é, extrapola suas categorias, exigindo uma reformulação ou criação de novas categorias que dêem conta daquilo que ele vê ${ }^{13}$.

O caráter histórico e particular da ciência ocidental é evidenciado pela forma como esta é representada na obra, porque essa ciência não consegue apreender nem descrever corretamente uma realidade cósmica, universal e antiga, regida por leis desconhecidas do homem. Com isso, poder-se-ia imaginar que o caráter de verdade da ciência é questionado. Entretanto, Lovecraft expressa a sensação causada quando os antigos paradigmas são abalados pelas novas teorias científicas do final do século XIX que, nas mais diversas áreas de conhecimento, exigiram novos modelos explicativos que substituíssem os antigos modelos clássicos ${ }^{14}$, não porque os muitos destes perdessem seu caráter de objetividade, mas porque não tinham mais a universalidade antes pretendida.

Cabe ressaltar que Lovecraft se considerava materialista e, como ele próprio dizia, fazia histórias fantásticas para suprir o seu desejo de suspender as leis da natureza e limitações do espaço e do tempo, nas quais ele acreditava ${ }^{15}$. Apesar de sua convicção, esse desejo expressa uma das características marcantes do modernismo, que é a tentativa de unir as tradições positivista e romântica do século XIX ${ }^{16}$ na busca de uma nova

13“As tentativas obsessivas de dizer 'o indizível' colocavam exigências extremas à elasticidade mental. Não só a literatura, mas toda a arte do período, parecia decidida a forçar a mente para além dos limites do próprio entendimento humano" McFARLANE, O Espírito do Modernismo, p. 56

14 "Assim, nos vinte anos entre 1895 e 1915, todo o quadro do universo físico, que havia se apresentado como a realização não só mais impressionante, mas também mais sólida do pensamento científico, foi posto em questão, e surgiram as primeiras tentativas de substituílo por um novo modelo" BULLOCK, A Dupla Imagem, p. 51

15"Thus my serious conception of reality is dynamically opposite to the fantastic position I take as an aesthete. In aesthetics, nothing interests me so much as the idea of strange suspensions of natural law (...). I think this kind of thing fascinates me all the more because I don't believe a word of it!" LOVECRAFT, autobiographical sketch, $§ 11$

16"A literatura recente não é, portanto, nem fundamentalmente realista, nem fundamentalmente romântica; é, melhor dito, eclética, conseqüência da opção entre muitos estados de espírito e pontos de vista" TAYLOR, op. cit, p. 302 
racionalidade ${ }^{17}$ que dê conta de explicar os novos processos e a nova realidade que vai se configurando com o advento da industrialização e da urbanização crescente, com todos os impactos sociais daí decorrentes.

\section{Mitologia de Lovecraft}

Lovecraft procura responder a isso, em suas tramas, através da criação de uma realidade que engloba a nossa. Ele cria toda uma realidade fantástica, antiqüíssima e insólita, hoje conhecida como ciclo de Cthullu, que tem um caráter mitológico porque explica a origem do cosmos num tempo muito anterior à existência do ser humano e dá sentido à natureza e a alguns eventos do mundo humano. Os elementos estranhos dos contos analisados pertencem a esse nível de realidade, por isso eles têm um caráter objetivo nos contos analisados, e quem os toma por sobrenatural são as personagens.

Por essa busca de criar realidades e universos alternativos, podemos aproximar Lovecraft de outros contemporâneos que fizeram um trabalho semelhante, tal como J.R.R. Tolkien (1892-1973), com "O Hobbit" - 1937, que criou um mundo "mítico" e "maravilhoso", mas realista em si; como Aldous Huxley (1894-1963), com "Admirável Mundo Novo" de 1931, que projeta no futuro alternativo as conseqüências da industrialização e do desenvolvimento científico da humanidade; e com George Orwell (19031950), com "1984" de 1949, que retrata uma sociedade alternativa ditatorial e socialista. Essas mitologias (ou distopias) são mais uma manifestação daquela busca de uma nova lógica para entender um mundo em mutação. Para McFarlane

“Nessa situação de fluidez crescente, o 'mito' (como logo sustentaria Sorel), apresentava-se como um recurso extremamente fecundo para impor uma ordem de tipo simbólico, ou mesmo poético, ao caos dos fatos cotidianos e oferecer a oportunidade - usando uma frase de Frank Kermode - de "produzir um curto-circuito no intelecto e libertar a imaginação que é reprimida pelo cientificismo do mundo moderno'. Nascido do irracional e obedecendo a uma lógica muito mais próxima às sugestões subjetivas e associativas do in-

\footnotetext{
${ }^{17} \mathrm{O}$ que contava [para o surrealismo] era reconhecer a capacidade da imaginação espontânea, não mediada por sistemas de controle racional, para extrair coesão do incoerente, e uma lógica aparentemente necessária do visivelmente ilógico ou mesmo impossível" HOBSBAWN,

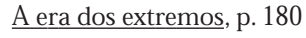


consciente do que à progressão formal do trabalho científico, o mito oferecia um novo tipo de percepção de realidades inconstantes dos fenômenos sociais, proporcionando - como viria a dizer Eliot, a respeito do mito de Joyce - 'uma maneira de controlar, ordenar, dar forma e sentido ao imenso paradoxo de futilidade e anarquia que é a história contemporânea." " 18

Na obra desses autores, a realidade alternativa tem uma forte consistência interna que dá uma sensação de verossimilhança muito grande porque aquilo que o leitor consideraria sobrenatural é vivido pelas personagens como algo real e cotidiano. Já na ficção de Lovecraft, ao contrário, as personagens sentem o sobrenatural como algo alheio às suas realidades, pois o autor parte do "mundo real" (tal como era entendido), velando todos os elementos estranhos a esse mundo, que é vislumbrado apenas por poucas pessoas. Uma outra característica da mitologia de Lovecraft é o medo, tratado logo a seguir.

\section{Medo}

A conseqüência da compreensão do sobrenatural para o protagonista lovecraftiano é o desencadeamento de um horror profundo em quem desvela essa realidade oculta ${ }^{19}$, pois o conhecimento daí advindo não pode ser suportado pela mente humana ${ }^{20}$. O medo, para Lovecraft, é o sentimento primordial da humanidade ${ }^{21}$ e, em seus contos, tem uma origem exterior ao sujeito, não sendo proveniente de ilusões ou quimeras por parte do protagonista.

A presença de elementos primordiais irracionais, que são responsáveis pelo horror frente ao sobrenatural, é o que une tanto o homem erudito quanto o rústico em seus contos. Aqui vemos uma influência da psicanálise de finais do século XIX ${ }^{22}$, pois esses elementos estão presentes também na obra de Freud (sob a forma de pulsões). Existe uma busca para definir o que há de comum em toda a humanidade e em todos os tempos por meio

${ }^{18}$ McFARLANE, "O Espírito do Modernismo", p. 64

19"What I saw in the glow of flashlight after I shot the unspeakable straggling object was so simple that almost a minute elapsed before I understood and went delirious" LOVECRAFT, Lurking Fear, § 63 (parte IV)

20"Science, already oppressive with its shocking revelations, will perhaps be the ultimate exterminator of human species - if separated species we be - for its reserve of unguessed horrors could never be borne by mortal brains if loosed upon the world" LOVECRAFT, Arthur Jermyn, parte I, § 1

21 "fear is our deepest and strongest emotion" LOVECRAFT, Notes on writing weird fiction, § 1

${ }^{22}$ TAYLOR, op. cit., p. 398 
de elementos irracionais e subconscientes, e não, como na tradição ocidental que vêm do iluminismo, pela razão humana.

Para Delumeau, "No sentido estrito do termo, o medo (individual) é uma emoção - choque, freqüentemente precedida de surpresa, provocada pela tomada de consciência de um perigo presente e urgente que ameaça, cremos nós, nossa conservação" 23 que tem um caráter ambíguo: é necessário à vida, pois nos livra de perigos, mas "se ultrapassa uma dose suportável, ele se torna patológico e cria bloqueios. Pode-se morrer de medo ou ao menos ficar paralisado por ele" ${ }^{24}$. Essa é a reação que os protagonistas de Lovecraft esboçam após o desvelamento do sobrenatural, cabendo nos perguntar qual a ameaça representada pela nova realidade que se apresenta diante das personagens.

No caso de Arthur Jermyn o medo é o da possibilidade de degeneração (perda da humanidade), que está latente, oriunda de sua família após o contato com o sobrenatural ${ }^{25}$, e diz respeito imediatamente às suas origens. No caso do protagonista do "Lurking Fear" é mais abrangente, porque as criaturas, com sua periculosidade e provável onipresença, podem por em risco toda a humanidade ${ }^{26}$. Assim, as criaturas deste último conto funcionam como uma síntese daquilo que causa o medo aos protagonistas de Lovecraft: a) a parte animalesca têm uma origem obscura; b) esta parte é mestiçada com uma família de ascendência importante (no caso, os Martense, de origem holandesa); c) o produto dessa mestiçagem é uma humanidade degenerada que, por seu caráter feroz e animalesco, é perigosa para todos; d) essas criaturas podem estar presentes em todo o mundo.

Punter relaciona esses medos presentes nos contos a temores vividos pelo autor:

"É difícil dizer qual é maior em Lovecraft: o seu medo do passado, principalmente na forma de um medo de civilizações primitivas e

\footnotetext{
${ }^{23}$ DELUMEAU, História do Medo no Ocidente, p. 23

${ }^{24}$ idem, p. 19

25"Madness was in all the Jermyns (...) The Jermyns never seemed to look quite right something was amiss, though Arthur was the worst, and the old family portraits in Jermyn House showed fine faces enough before Sir Wade’s time." LOVECRAFT, Arthur Jermyn, §3 (parte I). Foi o casamento de Wade com a "deusa empalhada", meio símio e meio humana, apresentada como filha de um comerciante português, no inicio do conto, que legou os estranhos traços físicos e psicológicos aos descendentes.

${ }^{26} \mathrm{~A}$ respeito do medo à espreita, o protagonista diz "The thing will haunt me, for who can say the extermination is complete, and that analogous phenomena do not exist all over the world? Who can, with my knowledge, think of the earth's unknown caverns without a nightmare dread of future possibilities?" LOVECRAFT, Lurking Fear, § 62 (parte IV)
} 
da Europa decadente corroendo os valores íntegros da Nova Inglaterra (e especialmente Providence, Rhode Island), ou o seu medo do futuro, manifesto em uma repulsa às máquinas, ao comercialismo e a tudo que podia viciar a ilusória estabilidade social à qual ele obcessivamente apegava-se." ${ }^{27}$

Aquela modernidade anteriormente mencionada teve suas especificidades nos Estados Unidos. Desde o final do século XIX, os processos de industrialização e de urbanização (das grandes e pequenas cidades), inter-relacionados, geraram uma nova sensibilidade, urbana, com valores e padrões de comportamento que, ao mesmo tempo, colocavam em xeque os valores tradicionais, oriundos de uma sociedade agrária, e apontavam para formação de uma sociedade de consumo (nos anos 20). $\mathrm{O}$ inchamento das cidades foi devido à chegada de estrangeiros (principalmente do leste e sul da Europa) e de pessoas do meio rural ${ }^{28}$. Nem todos gostaram dessas mudanças, e Lovecraft foi um desses. Apesar de seu entusiasmo diante das descobertas científicas de sua época, é conhecida a sua aversão tanto a imigrantes não brancos caucasianos, que ele considerava inferiores (pensamento esse corrente em sua época), quanto ao consumismo que, segundo ele, era uma degeneração da cultura.

O horror inominável também não era estranho ao mundo ocidental da época, pois fora sentido na Primeira Guerra Mundial. A capacidade de destruição propiciada pelo desenvolvimento tecnológico foi pela primeira vez vista pela humanidade, e os que participaram desta experiência tiveram a noção da fragilidade humana diante de todo o aparato bélico ${ }^{29}$. Assim, os seres descritos pelo autor, que geram um horror inominável em quem os vê, tinham sua contrapartida no mundo concreto, sob a forma de canhões e bombas. Quem se depara com a guerra moderna ou morre ou tem uma experiência marcante e inenarrável para toda a vida. Ao contrário do universo criado por Lovecraft, entretanto, nos deparamos com um universo técnico criado pelo próprio homem, cujas potencialidades sobrepujaram a escala humana ${ }^{30}$. Os deuses da técnica aplicada ao poderio militar, em nosso tempo, dormem nos arsenais das nações, manifestando-se hoje em guerras locais, através de bombas e metralhadoras. Se a ambição humana for longe o suficiente para despertá-los em escala global, sua fúria será su-

${ }^{27}$ PUNTER, The Literature of Terror, p. 40 (Tradução minha).

${ }^{28}$ Para detalhes, ver o artigo de LEE \& REINDERS, A perda da inocência.

${ }^{29}$ BENJAMIN, op. cit., p. 198

${ }^{30}$ BENJAMIN, A obra de Arte na Época da Reprodutibilidade Técnica, p. 174 
ficiente para extinguir a raça humana. Os deuses bélicos criados pela humanidade, nesse sentido, serão muito mais terríveis e inomináveis que as entidades do mundo de Lovecraft.

\section{BIBLIOGRAFIA}

BENJAMIN, Walter "O narrador" In: idem. Magia e Técnica, Arte e Política São Paulo: Brasiliense, 1985, pp. 197-221.

. "A Obra de arte na Era da Reprodutibilidade Técnica" In: idem. Magia e Técnica, Arte e Política São Paulo: Brasiliense, 1985, pp. 165-196. BESSIÈRE, I. Le récit fantastique. Paris: Larousse, 1974.

BOZZETTO, Roger. Le fantastique dans la literature des États-Unis. In: Europe, révue littéraire mensuelle, année $66, n^{\circ} 707$, Paris: Europe et Messidor, 1988.

BULLOCK, Alan. "A dupla Imagem” In: BRADBURY, Malcolm \& McFARLANE, James (orgs.) Modernismo: Guia Geral. São Paulo: Companhia das Letras, 1989, pp. 44-54.

DELUMEAU, Jean. História do Medo no Ocidente São Paulo: Cia das Letras, 1989.

FEAR, Jacqueline \& McNEIL, Helen. "Que foram os anos 20" In: BRADBURY, Malcolm \& TEMPERLEY, Howard (ed.). Introdução aos Estudos Americanos. Rio de Janeiro: Forense Universitária, s/d, pp. 246275.

FINNÉ, J. La littérature fantastique. Bruxelles: Université de Bruxelles, 1980.

HOBSBAWN, E. J. A Era dos Extremos: O Breve Século XX São Paulo: Cia das Letras, 1995.

JOSHI, S.T. H.P. Lovecraft, 2000, Extraído em 24/02/2003 de http:// www.themodernword.com/scriptorium/lovecraft.html.

LEE, Bryan \& Reinders, Robert. "A perda da Inocência" In: BRADBURY, Malcolm \& TEMPERLEY, Howard (ed.). Introdução aos Estudos Americanos. Rio de Janeiro: Forense Universitária, s/d, pp. 223-245.

LOVECRAFT, H.P. Facts Concerning the Late Arthur Jermyn and His Family (1920) Extraído em 01/07/2002 de http://www.gizmology.net/ lovecraft/works/lurking.htm.

. The lurking Fear (1922) Extraído em 01/07/2002 de http:// www.gizmology.net/lovecraft/works/a_jermyn.htm.

__. At the root (1918) Extraído em 19/09/2002 de http://

www.gizmology.net/lovecraft/works/theroot.htm. 
An autobiographical sketch [excerto da carta a R. Michel, de 20/07/ 1929) Extraído em 19/09/2002 de http://www.gizmology.net/lovecraft/ bio/autobiography.htm.

. Notes on Writing Weird Tales (1934) Extraído em 19/09/2002 de http://www.gizmology.net/lovecraft/works/weird.htm.

. O Horror Sobrenatural na Literatura (1927) Rio de Janeiro: Francisco Alves, 1987.

Trecho da carta a Rheinhart Kleiner (20 de Janeiro de 1916) Extraída em 19/09/2002 do site http://www.hplovecraft.com/life/interest/ authors.htm\#poe.

MARTIN, James Kirby et alii. America and its peoples. 3a ed. NY:

Longman, 1996.

McFARLANE, James. "O Espírito do Modernismo" In: BRADBURY, Malcolm \& McFARLANE, James (orgs.) Modernismo: Guia Geral. São Paulo: Companhia das Letras, 1989, pp. 55-73.

PUNTER, David. The Literature of Terror: A History of Gothic Fictions from 1765 to the present day 2a ed. NY: Longman, 1996, v. 2 (The modern gothic).

TAYLOR, Walter Fuller História das Letras Americanas São Paulo: Fondo de Cultura, 1967.

TODOROV, Tzvetan Introdução à Literatura Fantástica São Paulo: Perspectiva, 1992. 